\title{
East meets West: What is early cancer?
}

\author{
Robert H Riddell MD MRCPath FRCPC
}

RH Riddell. East meets West: What is early cancer? Can J Gastroenterol 1999;13(6):495-497. It has become increasingly apparent that the Japanese and Western systems of classifying dysplasia and carcinoma in the gastrointestinal tract are not the same. The implication of these differences is that in an article in a Western journal on gastrointestinal 'cancer' originating from Japan, it is often impossible to repeat the study to confirm or refute it because of these differences in definitions. 'Carcinoma' is diagnosed in Japan by virtue of its structural and cytological features but by invasion in the Western system. Adenoma does not mean a dysplastic lump in the Japanese system (although it can), but in most cases is similar to low grade dysplasia irrespective of the macroscopic and/or endoscopic appearances (hence flat and depressed adenomas in the Japanese system); however, most examples of high grade dysplasia in the Western system, as well as some low grade dysplasia, are 'cancer' in the Japanese system. Conversely, both have conceptual areas that are useful in the other's system.

Key Words: Adenoma; Carcinoma; Dysplasia; Endoscopy; Gastrointestinal cancer

\section{L'Est et l'Ouest se rencontrent : Qu'est-ce qu'un cancer précoce?}

RÉSUMÉ : On se rend de plus en plus compte que les systèmes japonais et occidentaux de classification des dysplasies et des carcinomes du tractus digestif sont différents. Cela suppose que les théories d'un auteur japonais publiées dans une revue occidentale sur le cancer digestif au Japon, sont souvent impossibles à vérifier, à confirmer ou à réfuter en raison des définitions différentes données aux termes. Le " carcinome " est diagnostiqué au Japon sur la base de ses caractéristiques structurales et cytologiques, alors que c'est sur la base de son invasivité qu'on l'évalue en Occident. L'adénome n'est pas une masse dysplasique selon le classement japonais (bien que cela soit possible), mais dans la plupart des cas, on le juge similaire à une dysplasie de bas grade, indépendamment des aspects macroscopiques et (ou) endoscopiques (d'où les adénomes plats ou en creux du système japonais). Par contre, la plupart des exemples de dysplasies avancées de même que certaines dysplasies de bas grade du système de classification occidental, sont des « cancers » selon le système japonais. À l'inverse, les deux systèmes recouvrent des notions qui leur sont mutuellement utiles.
A ttention has been drawn recently to the differences in the Eastern (Japanese, some European, some South American) and Western (North American, most European, some South American) classifications of gastric and colorectal dysplasia and carcinoma (1,2). Although these differences were known to exist, their precise nature and extent were not. Nevertheless, an increasing number of articles in the English language literature from Japan regarding cancer do not appear to distinguish between invasive and noninvasive neoplasia, as is traditionally done in the West. This becomes a serious problem with 'early' cancer because both mucosal (invasive and noninvasive) and submucosal cancers are included in the Japanese system (3), while in the Western system 'early carcinoma' means 'invasive carcinoma' limited to the lamina propria (upper gastrointestinal tract) or submucosa but (for those using the term) excluding 'in situ carcinoma' (large bowel). Lymph nodes may or may not be involved in both systems.

Further problems include the difference in definition of the word 'carcinoma'. In the Eastern system, this involves interpretation of the nuclear and structural changes, while the Western system is based on the presence of invasion. Prevalence and incidence figures from Japan are, therefore, not directly comparable with figures from the West. Further, survival figures that include noninvasive neoplasms, not surprisingly, are higher because there can be no mortality from these tumours.

Even if these differences are responsible for only a small proportion of the variations in survival, they are not widely appreciated. Research articles, especially those from Japan, dealing with 'early cancer' invariably contain examples of both noninvasive and invasive carcinoma, which is not a

Professor of Pathology, Department of Pathology, McMaster University Medical Centre, Hamilton, Ontario

Correspondence: Dr Robert H Riddell, McMaster University Medical Centre, PO Box 2000 Stn Lcd 1, Hamilton, Ontario

L8N 325. Telephone 905-521-2100 ext 6341, fax 905-577-0198, e-mail riddellr@fhs.mcmaster.ca 


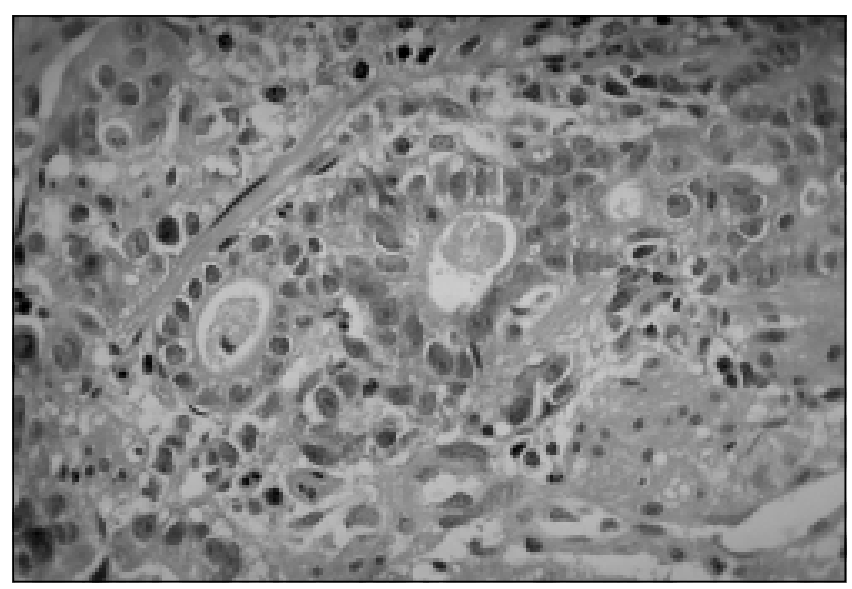

Figure 1) Irregular neoplastic glands infliltrating into the lamina propria, therefore, conforming to invasive carcinoma by Western criteria

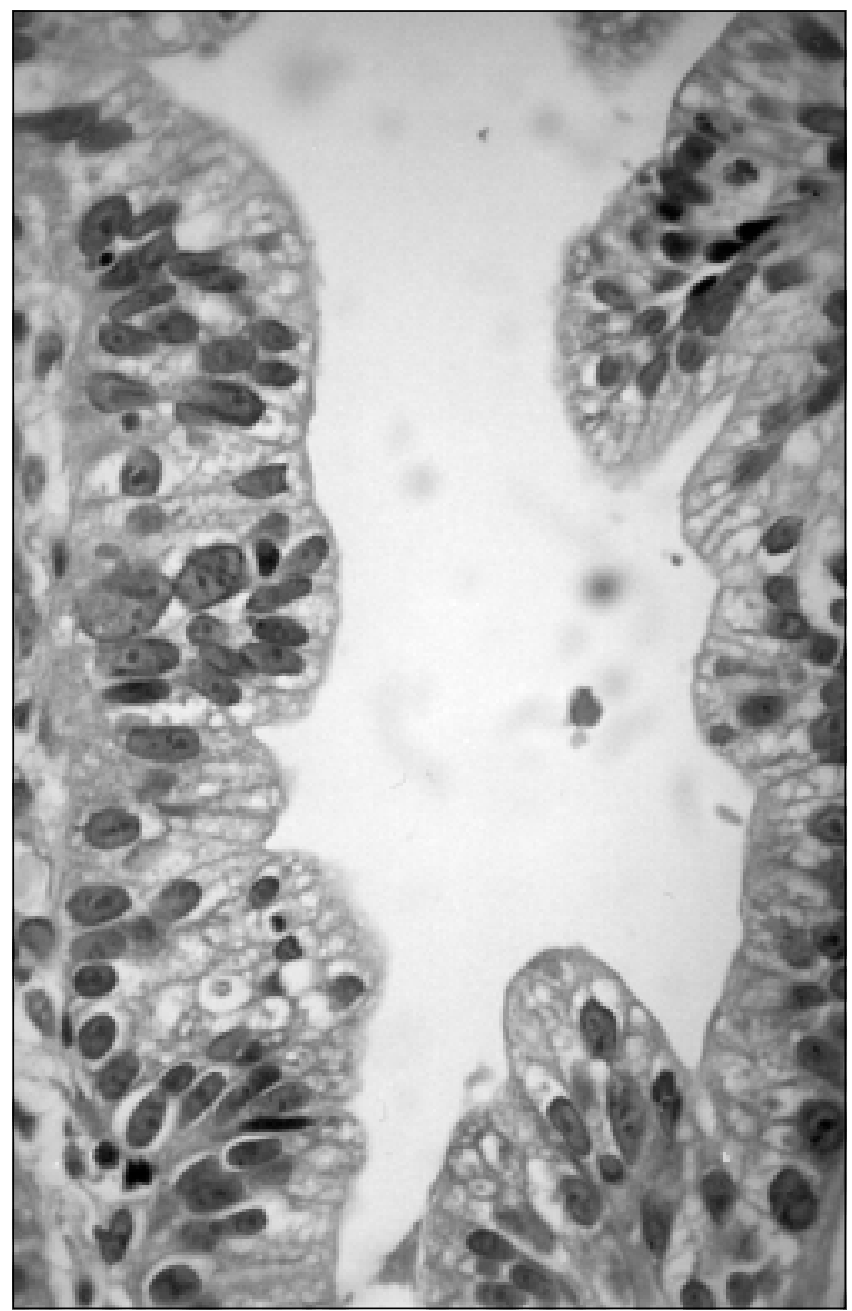

Figure 2) Gastric pit lined with hyperchromatic nucleoli that have also lost their normal polarity, therefore, conforming to the diagnosis of carcinoma by Japanese criteria

problem when using the Eastern system, but from a Western viewpoint, 'early cancer' may include adenomas, dysplasia in inflammatory bowel disease or invasive carcinomas, so that this distinction needs to be made for the work to be understood and confirmed.

\section{'WESTERN' TERMINOLOGY}

In countries with a Western style of terminology, by convention, 'dysplasia' is (and has been since 1983) unequivocally 'neoplastic but noninvasive lesions' (4). While used initially to describe lesions in inflammatory bowel disease (IBD), it is now generally used to describe lesions throughout the gastrointestinal tract as well as in other organs. In the gastrointestinal tract, dysplasia is the defining morphological feature for adenomas, dysplasia-associated lesions or masses in IBD when a lesion is identified, for dysplasia in IBD when it is not and for microadenomas when uni- and multicrypt adenomas are found in adenomatous polyposis coli. Because carcinoma in situ is noninvasive, for those who use the term, it also includes high grade dysplasia. 'Atypia', by the same convention, is a term applied to other forms of nuclear change. Initially this included all nondysplastic terms, including 'reactive' and 'regenerative', or 'reparative' lesions. Lesions that are not negative, reactive or dysplastic are called 'indefinite for dysplasia'. Dysplasia can be graded, typically into 'high grade' or 'low grade' (most of the data are in this form); others use 'mild', 'moderate' and 'severe'. 'Invasive carcinoma' in the West is by definition invasive and has metastatic potential. In the stomach, this occurs with invasion into the lamina propria of the mucosa or beyond, where tumour cells can invade capillaries or lymphatics to realize their metastatic potential (Figure 1). Biopsies can, therefore, be subdivided into those that are:

- negative for dysplasia - including reactive changes;

- indefinite for dysplasia;

- dysplastic - low grade or high grade (by definition noninvasive); and

- invasive carcinoma.

\section{'EASTERN' (JAPANESE) TERMINOLOGY}

In countries using the Japanese terminology, all epithelial neoplasms are classified as either 'adenoma' or 'carcinoma'. However, the term 'carcinoma' is used for lesions that are structurally and/or cytologically malignant irrespective of the presence of invasion (Figure 2). 'Adenoma' refers to benign (noninvasive) neoplastic lesions not included as carcinoma. Both 'adenoma' and 'carcinoma' are used irrespective of the macroscopic shape of the lesion. In Japanese, the word pronounced 'ikeisei' has two different written forms, one of which is translated as 'atypia' and the other as 'dysplasia'. The term 'atypia' is used to express cytological and/or structural abnormalities. 'Dysplasia' is not frequently used and may denote either the grade of atypia or lesions with atypia insufficient for a definite diagnosis of neoplasia ('indefinite for dysplasia' in Western terminology), or may be used in an identical manner to that of the Western term, especially in the esophagus. For concise interpretation of gastric endoscopic biopsies, the Japanese Group Classification is used in conjunction with this nomenclature as follows. 
- Group I: Normal gastric mucosa and benign (non-neoplastic) lesions with no atypia.

- Group II: Lesions showing atypia but benign (non-neoplastic).

- Group III: Borderline lesions between benign (non-neoplastic) and malignant lesions (refers primarily to adenomas).

- Group IV: Lesions strongly suspected of being carcinoma (comment: includes technical problems that preclude diagnosis if the suspected carcinoma is small or artifactually damaged).

- Group V: Carcinoma (as defined above)

\section{INTERPRETATION OF GASTRIC LESIONS: SIGNIFICANCE OF INCONSISTENT CRITERIA}

Although many of the words are the same, they have very different meanings in the two systems. These differences were highlighted during Digestive Diseases Week (United States) in May 1996, when a Japanese paper by Uemura and colleagues (5) from Hiroshima became one of the best attended and most hotly discussed papers. In this study, 132 patients had undergone endoscopic resection of early gastric cancers. This involves submucosal injection of saline, often with adrenalin, to raise the lesion off of the submucosa, and then endoscopic snaring and excision - endoscopic mucosal resection (EMR); this is fairly standard practice in Japan. These patients were then randomly assigned into half in whom Helicobacter pylori was eradicated and half in whom it was not. Follow-up endoscopy was carried out over the next two years when it was expected that approximately $10 \%$ would develop a second carcinoma. This happened in the untreated group but not in the treated group. This was, therefore, good evidence that eradicating $\mathrm{H}$ pylori prevented the development of carcinoma. This appeared to be a real breakthrough in the prevention of gastric carcinoma. However, Dr Ronald Schlemper, a Dutch gastroenterologist working in Japan, appreciated that when the Japanese speak about 'carcinoma', their definition may be different from that of most of the audience. Something may well have happened by eradicating $H$ pylori, but it was probably not what most thought, and it was even possible that none of the lesions were invasive at all. To my knowledge these slides have never been examined by an external Western pathologist.

On his return to Japan, Dr Schlemper talked to his pathology colleagues. Japanese and Western pathologists were then invited to examine a series of biopsies and subsequent EMRs from the same patient, inviting them to give both a diagnosis and the criteria for the diagnosis. The results showed that there were clearly two completely different systems for the diagnosis of carcinoma; one was based primarily on nuclear and structural criteria, even in noninvasive lesions, in both the stomach and large bowel, and the other was based on invasion into either the lamina propria in the stomach or the submucosa in the large bowel $(1,2)$.

In parallel with this study, Lauwers et al (6) carried out a similar study on a much larger series of gastric biopsies pro- vided by Dr Shimizu in Japan. However, Eastern and Western pathologists were asked to classify biopsies in their own classification system. This not only confirmed the dual systems but also found that neither Eastern nor Western pathologists were very reproducible within their own systems. The question increasingly became one of whether, and how, it might be possible to reconcile both systems.

\section{RECONCILIATION OF EASTERN AND WESTERN SYSTEMS}

In a study carried out with Professor Iwafuchi, from Japan (7), examining the same set of slides independently, we found that in the Japanese system, 'tubular' carcinoma is largely equivalent to 'intestinal' carcinoma in the West, but herein lay a major problem.

The term 'carcinoma' as used in the Japanese system was found to include in the Western system every invasive carcinoma, all high grade dysplasia and a small proportion of low grade dysplasia. Re-examination of the slides with low grade dysplasia (Western) reported as showing carcinoma (Japanese) had enlarged, rounded to cigar-shaped nuclei with enlarged nucleoli with loss of nuclear polarity. Changes such as these were seen in some low grade, and all high grade dysplasia and invasive carcinoma.

While this system can be finely tuned between these two observers, in the studies by Lauwers et al (6) and by Schlemper et al $(1,2)$, there was also interobserver variation. The corollary to this is that it might not be necessary to fine-tune a joint system so precisely, but this seems a convenient comparison. At the interface of low grade dysplasia and high grade dysplasia in the West, it might even be possible to directly equate high grade dysplasia of the Western system with the noninvasive part of carcinoma in the Japanese system with little loss of sensitivity, if Japanese pathologists were prepared to make that distinction. Asking those using the Japanese system to note the presence of invasion would allow them to use the Western system, if necessary, when writing for Western journals. Conversely, Western pathologists could likely use the Eastern system, when necessary, by being more aware of nuclear changes that include change of shape, loss of polarity in neoplastic and enlarged nucleoli.

\section{REFERENCES}

1. Schlemper RJ, Itabashi M, Kato Y, et al. Differences in diagnostic criteria for gastric carcinoma between Japanese and Western pathologists. Lancet 1997;349:1725-9.

2. Schlemper RJ, Itabashi M, Kato Y, et al. Differences in the diagnostic criteria used by Japanese and Western pathologists to diagnose colorectal carcinoma. Cancer 1998;82:60-9.

3. Japanese Research Society for Gastric Cancer. Japanese classification of gastric carcinoma, 1st English edn. Tokyo: Kanehara, 1995.

4. Riddell RH, Goldman H, Ransohoff DF, et al. Dysplasia in inflammatory bowel disease. Standardized classification with clinical implications. Hum Pathol 1983:14:931-68.

5. Uemura N, Mukai T, Okamoto S, et al. Helicobacter pylori eradication inhibits the growth of intestinal type of gastric carcinoma in initial stage. Gastroenterology 1996:110:A282. (Abst)

6. Lauwers GY, Shimizu M, Correa P, et al. Evaluation of gastric biopsies for neoplasia: differences between Japan and the West. Mod Pathol 1998;11:66A. (Abst)

7. Riddell RH, Iwafuchi M. Problems arising from Eastern and Western classification systems for gastrointestinal dysplasia and carcinoma. Are they resolvable? Hepatology 1998:33;197-202. 


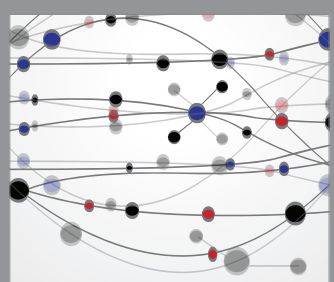

The Scientific World Journal
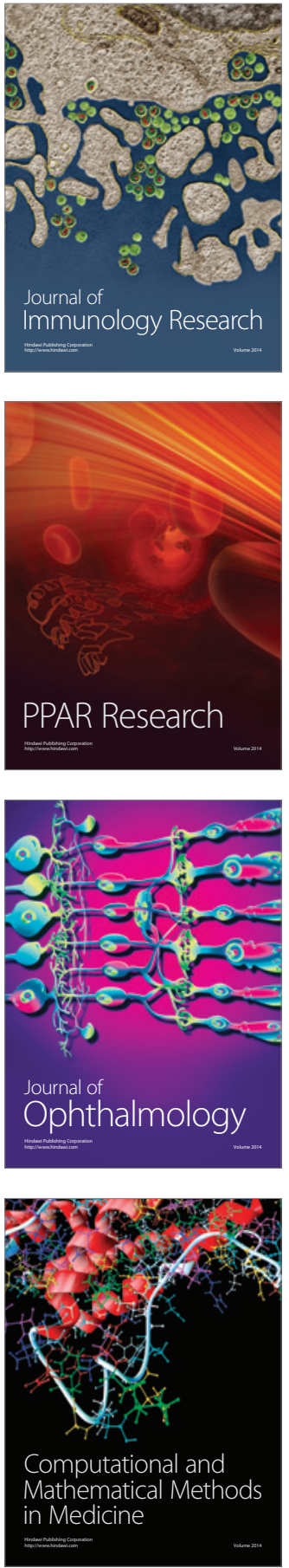

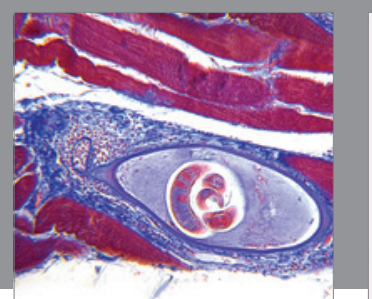

Gastroenterology Research and Practice

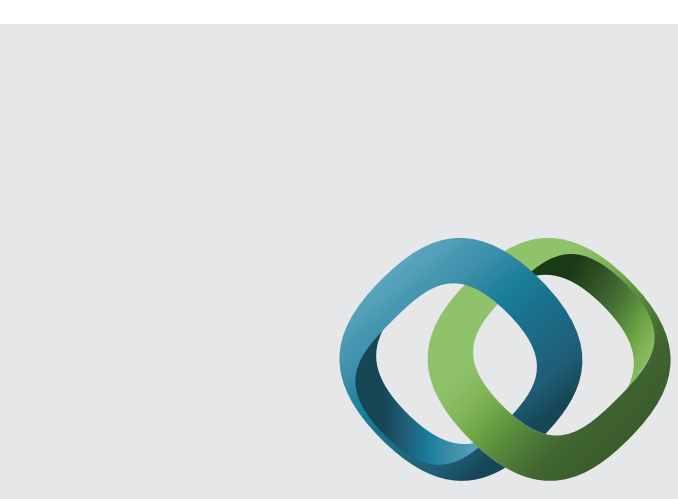

\section{Hindawi}

Submit your manuscripts at

http://www.hindawi.com
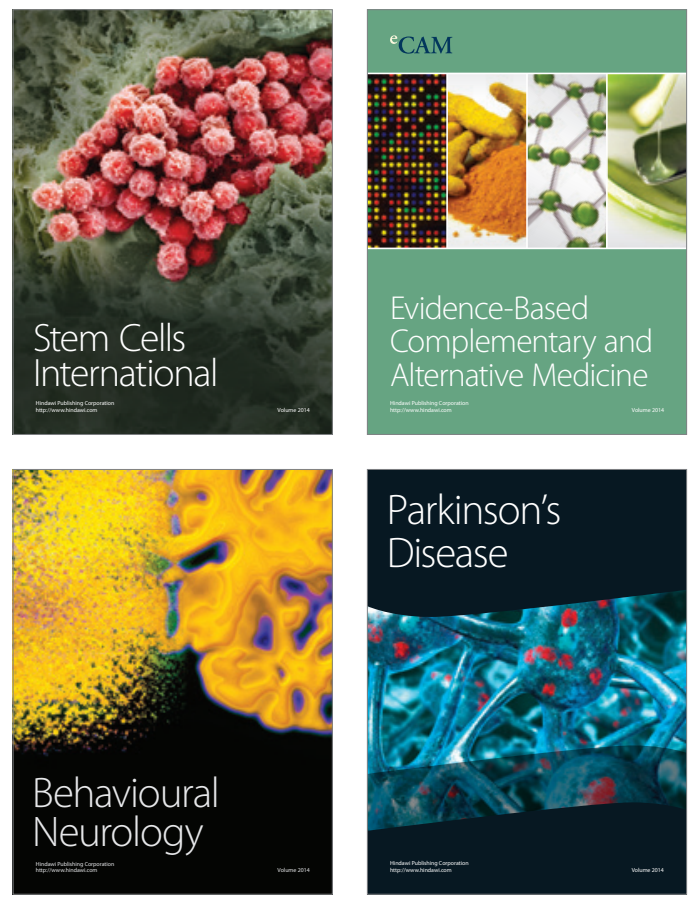
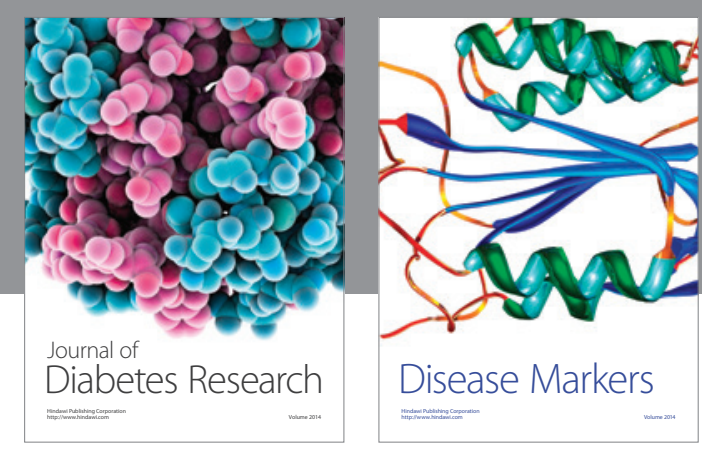

Disease Markers
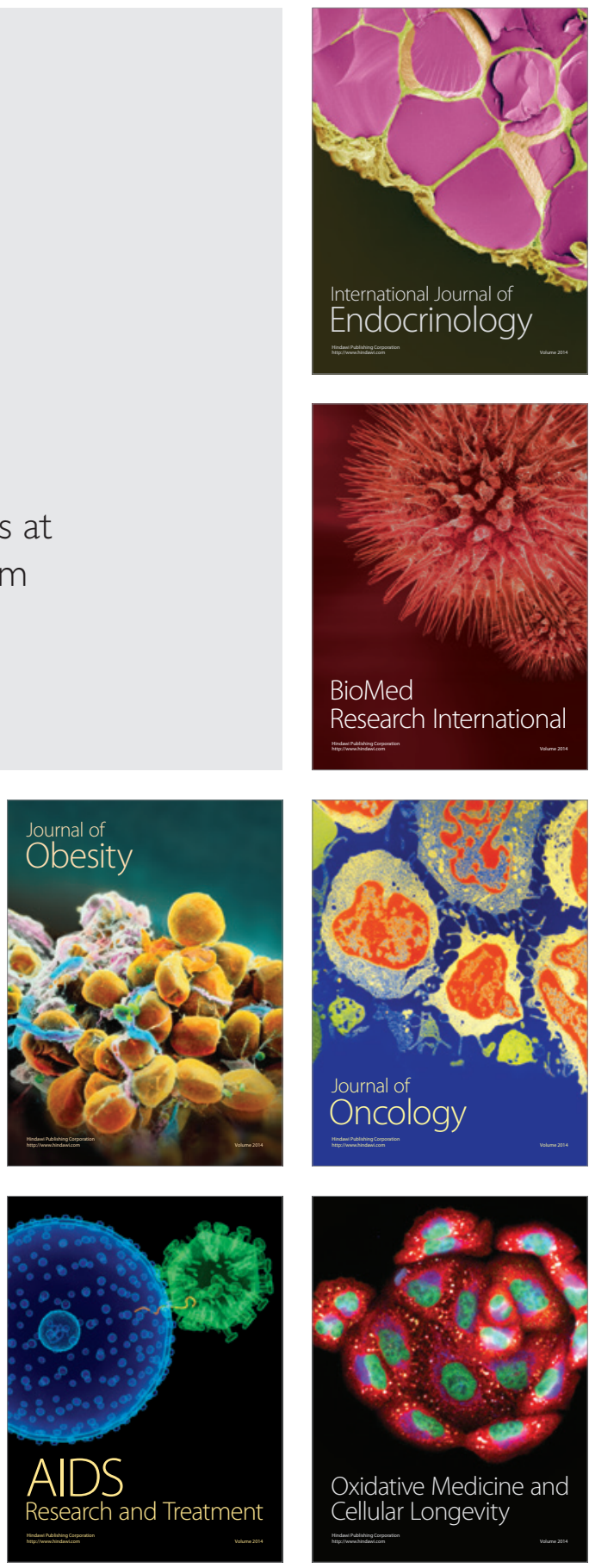